\title{
George Cecil Losh Saul
}

Many tributes have been paid to the memory of Captain G. C. L. Saul, who died on 14 July, both in a professional and in a personal capacity; but it would ill-become the Institute not to add its tribute to one to whom it owes so much.

Quiet and dignified in manner, Captain Saul possessed personal qualities of integrity, sympathetic understanding and kindness, allied to high professional competence and experience; he inspired confidence. It was these qualities which made him the natural choice as Chairman of the Original Steering Committee, which was responsible for the initial formulation of the Institute's aims, leading in due course to the Inaugural Meeting on 12 March 1947; and it was inevitable that he should be elected, at that meeting, to be Chairman of the Provisional Council, which held office until the first Annual General Meeting on 19 September 1947. During this all-important period in the Institute's history, he guided its affairs with generosity of spirit and of his time, with true friendship, and leaning heavily on his experience in the recent formation of The Honourable Company of Master Mariners, with great expertise. The Institute was formed to bring together the widely different fields of interest in navigation; and, although the members of the Provisional Council were animated with this common purpose, it required the chairmanship of a man like Saul, whom all respected, to fuse their ideas into a workable constitution.

It was typical that he should accept the onerous post of Treasurer in the first Council, a post which he retained for so long, until it was clear that the Institute was financially viable. Until a few months ago he continued to give the strongest support to the Institute, both with advice and with active attendance at meetings. He was a true friend of the Institute and it was a great source of pleasure to him that it has so flourished; much of that success can be attributed firmly to his personal influence and wisdom. 